\title{
Evaluation of the physicochemical properties of starch isolated from thinned young 'Fuji' apples compared to corn and potato starches
}

\author{
Han-Sol Park, Hun-Sik Chung* \\ Department of Food Science and Technology, Pusan National University, Miryang 50463, Korea
}

\begin{abstract}
Apple thinning is performed to enhance the mature fruit size and quality; however, most thinned young fruits, which contain a high starch content compared to that in mature fruits, are discarded. To increase the utilization of thinned apples, it is necessary to analyze the various characteristics of the starch isolated from these fruits. We investigated the chemical, morphological, pasting, digestive, and syneresis properties of the starch from young 'Fuji' apples thinned 60 days after full bloom, and compared them with those of com and potato starches (controls). The apparent amylose content was higher in apple starch (33.6\%) than in com starch $(\mathbf{2 9 . 8 \%})$, and the phosphorous contents of apple and potato starches were 13.0 and $49.2 \mathrm{mg} / 100 \mathrm{~g}$, respectively. Apple starch granules were mostly spherical, hemispherical, and split in shape and had a C-type X-ray pattern. These granules were smaller than those of com and potato starches. The swelling power followed the order of potato $>$ apple $>$ com starch, with pasting temperatures of $65.8,70.2$, and $77.1^{\circ} \mathrm{C}$, respectively. Potato starch had the highest peak viscosity, while apple starch had the highest hold and final viscosities and in vitro digestibility. Apple starch had lower syneresis than the other two starches. These findings show that young 'Fuji' apple starch displays unique properties that could be useful for industrial applications.
\end{abstract}

Key words : apple starch, physicochemical property, pasting property, digestibility, syneresis

\section{Introduction}

'Fuji' is an apple cultivar that has been increasingly cultivated worldwide (Mannucci et al., 2017). During development, many young fruits are removed from the trees in a process referred to as thinning, which helps to enhance the size and quality of the mature fruits (Chun et al., 2012). Only a small portion of thinned young apples are used for the production of functional compounds, such as polyphenols, and processed foods, with the vast majority being discarded (Zheng et al., 2012). Unlike mature apples, young apples have a high starch content and can therefore function as valuable starch sources (Song et al., 2003). Unfortunately, little is known about the starch properties of thinned young
'Fuji' apples, limiting their general and industrial applications. Starch is a polysaccharide composed of glucose monomers connected by glycosidic bonds and is the primary carbohydrate stored in plants (Singh et al., 2003). The granular form of starch is typically composed of two types of molecules: linear amylose and branched amylopectin (Sarka and Dvoracek, 2017). Depending on its physicochemical characteristics, starch is industrially used as a raw material for malting and fermentation, and for the production of thickeners, colloidal stabilizers, gelling agents, bulking agents, water retention agents, and adhesives (Singh et al., 2003). Starches from different botanical sources and different cultivars of the same crops have been reported to possess distinct physicochemical characteristics (de Barros Mesquita

\footnotetext{
*Corresponding author. E-mail : hschung@pusan.ac.kr, Phone : +82-55-350-5352, Fax : +82-55-350-5359

Received 11 May 2021; Revised 01 July 2021; Accepted 05 July 2021.

Copyright (c) The Korean Society of Food Preservation.

This is an Open Access article distributed under the terms of the Creative Commons Attribution Non-Commercial License (http://creativecommons.org/licenses/by-nc/4.0) which permits unrestricted non-commercial use, distribution, and reproduction in any medium, provided the original work is properly cited.
} 
et al., 2016; Singh et al., 2003). Therefore, it is crucial to identify the unique properties of the starches from different sources before their application. Starches from corn and potatoes have been characterized and used commercially (Singh et al., 2003). Unlike these starches, the physicochemical properties of apple starch, particularly that from 'Fuji' apples, have not been well characterized and no practical use has been found for them. Therefore, it is necessary to investigate the properties of apple starch and to compare them with the properties of well-known potato and corn starches.

It was found that there are significant differences in the structure, amylose content, and pasting properties of apple starches from different cultivars, such as 'Gala', 'Golden Delicious', 'Granny Smith', 'Jersey Mac', 'Jonagold', and 'Royal Gala' (Stevenson et al., 2006). Previous studies reported that the 'Fuji' apple starch content is the highest at 70 days after full bloom (Song, 2003) and rapidly decreases as the fruit matures (Fan et al., 1995). The starch contents of 'Golden Delicious' and 'Cox's Orange Pippin' apples decreased almost to zero during storage (Gorin et al., 1978). The morphological properties of starch from the 'Jonagold' (Ohmiya and Kakiuchi, 1990) and 'Mutsu' (Kovács and Eads, 1999) apple cultivars have also been reported. However, the phosphorous content, swelling power, solubility, digestibility, and syneresis of apple starch have not yet been described. The above reports indicate that the apple starch properties are dependent on the cultivar; therefore, we expect that 'Fuji' apple starch will differ from other apple starches and corn and potato starches.

The objective of this study was to investigate the chemical, morphological, pasting, digestive, and syneresis properties of the starch isolated from thinned young 'Fuji' apples, and compare them to those of potato and corn starches. The results of this study are expected to provide a better understanding of the starch obtained from thinned young apples for their effective utilization.

\section{Materials and methods}

\section{Materials}

Young 'Fuji' apples (Malus domestica Borkh.) thinned 60 days after full bloom were collected from a commercial farm in the Miryang region of Gyeongsangnam-do, South
Korea, immediately transported to the laboratory and subjected to starch isolation. The average weight of the fruit was $25.81 \pm 8.05 \mathrm{~g}$. Corn and potato starches were purchased from Samchun Pure Chemical Co. (Pyeongtaek, South Korea). Amylose from potato (A0512), amylopectin from maize (10120), pancreatin from porcine pancreas (P7545), amyloglucosidase from Aspergillus niger (A7095), and a glucose assay kit (GAGO20) were purchased from SigmaAldrich (St. Louis MO, USA). All other chemicals used for the analyses were obtained from commercial sources and were of high purity grade.

\section{Starch isolation}

Whole apples were crushed and filtered through nonwoven fabrics. The filtrate was centrifuged at 3,000 rpm for $10 \mathrm{~min}$ to precipitate the starch. The precipitate was collected, dispersed in distilled water, and passed through a $0.147 \mathrm{~mm}$ sieve. The purification process involving the discarding of supernatant and dispersing the precipitate in distilled water was repeated several times. The purified starch was then dried in an oven at $35^{\circ} \mathrm{C}$ for $24 \mathrm{~h}$, ground, and passed through a $0.147 \mathrm{~mm}$ sieve.

\section{Determination of amylose and phosphorus contents}

The apparent amylose content of starch was determined according to the procedure described by Williams et al. (1970). Briefly, the starch sample (20 mg) was placed in a beaker and $0.5 \mathrm{~N} \mathrm{KOH}(10 \mathrm{~mL})$ was added and dispersed for $10 \mathrm{~min}$. The mixture was diluted to a final volume of $100 \mathrm{~mL}$ using distilled water, and $20 \mathrm{~mL}$ of the diluted solution was collected and neutralized with $0.1 \mathrm{~N} \mathrm{HCl}(10$ $\mathrm{mL}$ ). Then, the neutralized sample was treated with an iodine solution ( $\left.1 \mathrm{~mL}, 0.2 \% \mathrm{I}_{2}+2 \% \mathrm{KI}\right)$ and diluted to 100 $\mathrm{mL}$ using distilled water. After reacting for $20 \mathrm{~min}$, the absorbance of the solution was measured at $680 \mathrm{~nm}$ using a spectrophotometer (UV-1800, Shimadzu, Kyoto, Japan). A standard curve was prepared using amylose and amylopectin standards mixed at known ratios.

The phosphorous content of starch was determined using the method described by Noda et al. (2004). Briefly, the starch sample $(0.2 \mathrm{~g})$ was digested using $\mathrm{HNO}_{3}$. The phosphorus content in the digestion was measured as inorganic phosphorus, using the vanado-molybdate method For the assay, $2 \mathrm{~mL}$ of the starch digestion solution, $3 \mathrm{~mL}$ 
of distilled water, $0.5 \mathrm{~mL}$ of $60 \%$ perchloric acid, $1.5 \mathrm{~mL}$ of $20 \mathrm{mM}$ ammonium vanadate solution containing $2.4 \%$ perchloric acid, and $3.0 \mathrm{~mL}$ of $3.53 \%$ ammonium molybdate solution were mixed together and kept for $30 \mathrm{~min}$. Finally, the absorbance was measured at $420 \mathrm{~nm}$ using a spectrophotometer (UV-1800, Shimadzu).

\section{Determination of morphology and particle size}

Starch morphology was examined using scanning electron microscopy (SEM, S-3500N, Hitachi Co., Tokyo, Japan). Briefly, the starch sample was spread onto a carbon tape attached to the top of the stub and coated with gold under vacuum using a SEM ion sputter coater. The coated starch was visualized between 500 and 5,000× magnification at 15 $\mathrm{kV}$. The starch particle size was measured using a laser diffraction particle size analyzer (LS13 320, Beckman Coulter Inc., Fullerton, CA, USA). For this, starch (0.5 g) was dispersed in isopropyl alcohol $(10 \mathrm{~mL})$, and the average particle diameter was measured in the range of 0.04 to $2,000 \mu \mathrm{m}$.

\section{$\mathrm{X}$-ray diffraction analysis}

The X-ray diffraction pattern of the starch was obtained using an X-ray diffractometer (Empyrean Series 2, Malvern Panalytical, Almelo, Netherlands) with the following specifications: $\mathrm{Cu} \mathrm{K} \alpha$, voltage $=40 \mathrm{kV}$, current $=30 \mathrm{~mA}$, filter $=\mathrm{Ni}$, scanning speed $=0.017^{\circ} / \mathrm{min}$, and diffraction angle $=4-40^{\circ}$.

\section{Measurement of swelling power and solubility}

The swelling power and solubility of the starch were measured at $40,50,60,70,80$, and $90^{\circ} \mathrm{C}$ as proposed by Schoch (1964). Suspensions of starch (0.5 g) in distilled water $(30 \mathrm{~mL})$ were incubated at the specified temperature in a water bath for $30 \mathrm{~min}$ with shaking at $150 \mathrm{rpm}$. The samples were then cooled to room temperature, centrifuged $\left(4^{\circ} \mathrm{C}, 6,000 \mathrm{rpm}, 30 \mathrm{~min}\right)$, and the supernatant and sediment were isolated for further analysis. The weight of the sediment was measured immediately. The supernatant was dried at $105^{\circ} \mathrm{C}$ to obtain the weight of soluble starch. The swelling power and solubility were calculated using the following equation:

$$
\begin{aligned}
& \text { Swelling power }= \\
& \qquad \frac{\text { Weight of sediment }}{\text { Weight of starchch } \times(100-\% \text { solubility })}
\end{aligned}
$$

$$
\text { Solubility }(\%)=\frac{\text { Dried weight of supernatant }}{\text { Weight of starch }} \times 100
$$

\section{Determination of pasting properties}

The starch pasting properties were determined using a Rapid Visco-Analyzer (RVA-4, Newport Scientific, Warriewood, NSW, Australia). Starch suspensions were prepared for analysis by adding distilled water $(25 \mathrm{~mL})$ to starch $(3 \mathrm{~g})$ and stirring at $960 \mathrm{rpm}$. The suspensions were transferred to an RVA set at $50^{\circ} \mathrm{C}$ and stirred for $1 \mathrm{~min}$ at $160 \mathrm{rpm}$ using a plastic paddle. The heating program was as follows: heated to $95^{\circ} \mathrm{C}$ at a rate of $12^{\circ} \mathrm{C} / \mathrm{min}$, maintained at $95^{\circ} \mathrm{C}$ for $2.5 \mathrm{~min}$, cooled to $50^{\circ} \mathrm{C}$ at a rate of $12^{\circ} \mathrm{C} / \mathrm{min}$, and maintained at $50^{\circ} \mathrm{C}$ for $1 \mathrm{~min}$.

\section{Measurement of in vitro digestibility}

The In vitro digestibility of starch was measured using the method described by Englyst et al. (1992). Digestive enzymes were produced by mixing a pancreatin solution $(2.7 \mathrm{~mL})$ and amyloglucosidase $(0.4 \mathrm{~mL})$. Briefly, pancreatin from the porcine pancreas $(0.45 \mathrm{~g})$ was dispersed in distilled water $(4 \mathrm{~mL})$ for $10 \mathrm{~min}$, centrifuged $\left(4^{\circ} \mathrm{C}, 10,000 \mathrm{rpm}, 10\right.$ $\mathrm{min}$ ), and the supernatant was collected. An amyloglucosidase solution was prepared by mixing amyloglucosidase from $A$. niger $(0.32 \mathrm{~mL})$ with distilled water $(0.4 \mathrm{~mL})$. For the analysis, starch $(100 \mathrm{mg})$, sodium acetate buffer $(4 \mathrm{~mL}, \mathrm{pH}$ 5.2), digestive enzymes ( $1 \mathrm{~mL}$ ), and 10 glass beads $(4 \mathrm{~mm}$ in diameter) were stirred for specific times $(0,20,60,120$, and $180 \mathrm{~min}$ ) in a shaking water bath at $37^{\circ} \mathrm{C}$ and $170 \mathrm{rpm}$. The digested starch solution $(0.1 \mathrm{~mL})$ was mixed with an $80 \%$ ethanol solution to stop the reaction, centrifuged $\left(4^{\circ} \mathrm{C}\right.$, 3,000 rpm, $10 \mathrm{~min}$ ), and used for the analysis. The glucose content of the hydrolyzed starch sample solution was measured using a glucose assay kit. The rapidly digestible starch (RDS) content was calculated from the quantity of glucose generated within $20 \mathrm{~min}$, and the slowly digestible starch (SDS) content was calculated from the quantity of glucose generated between 20 and $120 \mathrm{~min}$. The resistant starch (RS) was calculated by subtracting the RDS and the SDS content from 100 .

\section{Measurement of syneresis}

The syneresis of starch was measured by repeating the freeze-thaw cycle of the starch gel. Briefly, starch gels were 
prepared by dispersing a $10 \%$ starch suspension at $25^{\circ} \mathrm{C}$ for $10 \mathrm{~min}$, heating in a shaking water bath $\left(95^{\circ} \mathrm{C}, 150 \mathrm{rpm}, 30\right.$ min), followed by cooling at $4^{\circ} \mathrm{C}$ for $1 \mathrm{~h}$. The starch gels were frozen for $20 \mathrm{~h}$ at $-20^{\circ} \mathrm{C}$ and then thawed for $3 \mathrm{~h}$ at $30^{\circ} \mathrm{C}$. This constituted one freeze-thaw cycle, after which the sample was centrifuged ( $\left.4^{\circ} \mathrm{C}, 3,000 \mathrm{rpm}, 1 \mathrm{~h}\right)$. Subsequently, the water that had separated from the gel was removed, and the gel was weighed to calculate the syneresis by using the following equation:

$$
\text { Syneresis }(\%)=\frac{\text { Weight of separated water }}{\text { Weight of starch gel }} \times 100
$$

After the measurement, the gels were subjected to up to five freeze-thaw cycles, and the cumulative syneresis was obtained.

\section{Statistical analysis}

The results were calculated using IBM SPSS statistics (23.0, IBM Corp., Armonk, NY, USA) to determine the means and standard deviations. The significance values between samples were analyzed using one-way analysis of variance and Duncan's multiple range tests at a significance level of $\mathrm{p}<0.05$.

\section{Results and discussion}

\section{Comparison of amylose and phosphorus contents}

The amylose content plays a central role in the physicochemical parameters of starch (de Barros Mesquita et al., 2016). It can vary between botanical sources and within the same botanical variety owing to differences in the geographical origin and culture conditions (Alcazar-Alay and Meireles, 2015). The apparent amylose contents of the 'Fuji' apple, corn, and potato starches are listed in Table 1. The apparent amylose content of apple starch (33.6\%) was significantly higher than that of corn starch $(29.8 \%)(p<0.05)$; however, there was no significant difference between that of apple starch and that of potato starch (33.6-33.8\%) ( $\mathrm{p}>0.05)$. The apparent amylose content of 'Fuji' apples is lower than the reported apparent amylose content of the starches isolated from other apple varieties, including 'Gala', 'Golden Delicious', 'Granny Smith', 'Jersey Mac', 'Jonagold', and 'Royal Gala' apple (39.8\% to $48.1 \%)$ (Stevenson et al., 2006), which may be due to differences in apple varieties, fruit maturity, and the measurement techniques used (Duan et al., 2012; Fan et al., 1995; Stevenson et al., 2006).

Phosphorus is one of the minerals present in starch granules and significantly affects its functional characteristics (Alcazar-Alay and Meireles, 2015). The phosphorus contents of the apple, corn, and potato starches are listed in Table 1. The phosphorous content of the apple starch was 13.0 $\mathrm{mg} / 100 \mathrm{~g}$, which was significantly lower than that of potato starch $(49.2 \mathrm{mg} / 100 \mathrm{~g})(\mathrm{p}<0.05)$, but higher than that of corn starch $(11.3 \mathrm{mg} / 100 \mathrm{~g})$. It has been reported that potato starch has a higher concentration of phosphorous than starches from other botanical sources, and the phosphorus content has been found to have a significantly positive correlation with starch viscosity (Noda et al., 2004). The phosphorous content of other apple varieties has not yet been reported.

\section{Comparison of morphology and granule size}

'Fuji' apple starch granules were spherical, hemispherical, and broken spherical in shape (Fig. 1), resembling the starches obtained from 'Gala', 'Golden Delicious', 'Granny Smith', 'Jersey Mac', 'Jonagold', and 'Royal Gala' apples (Stevenson et al., 2006). These shapes were distinct from those of the starch granules of corn (angled polyhedron with grooves) and potato (smooth and round) (Fig. 1). Interestingly, the irregular shape of the starch granules from 'Mutsu' apples was found to shift to a gradually smaller and rounder

Table 1. Chemical composition and mean granule size of 'Fuji' apple, com, and potato starches

\begin{tabular}{cccc}
\hline Properties & Apple starch & Corn starch & Potato starch \\
\hline Amylose content $(\%)$ & $33.63 \pm 0.43^{\mathrm{a})}$ & $29.82 \pm 0.60^{\mathrm{b}}$ & $33.79 \pm 0.57^{\mathrm{a}}$ \\
Phosphorous content $(\mathrm{mg} / 100 \mathrm{~g})$ & $13.02 \pm 0.40^{\mathrm{b}}$ & $11.26 \pm 0.13^{\mathrm{c}}$ & $49.17 \pm 0.94^{\mathrm{a}}$ \\
Mean granule size $(\mu \mathrm{m})$ & $7.48 \pm 0.10^{\mathrm{b}}$ & $23.00 \pm 3.46^{\mathrm{b}}$ & $35.24 \pm 1.71^{\mathrm{a}}$ \\
\hline
\end{tabular}

${ }^{1)}$ Means \pm SD $(n=3)$ in a row followed by the same letter are not significantly different by Duncan's multiple range test ( $\left.\mathrm{p}<0.05\right)$. 

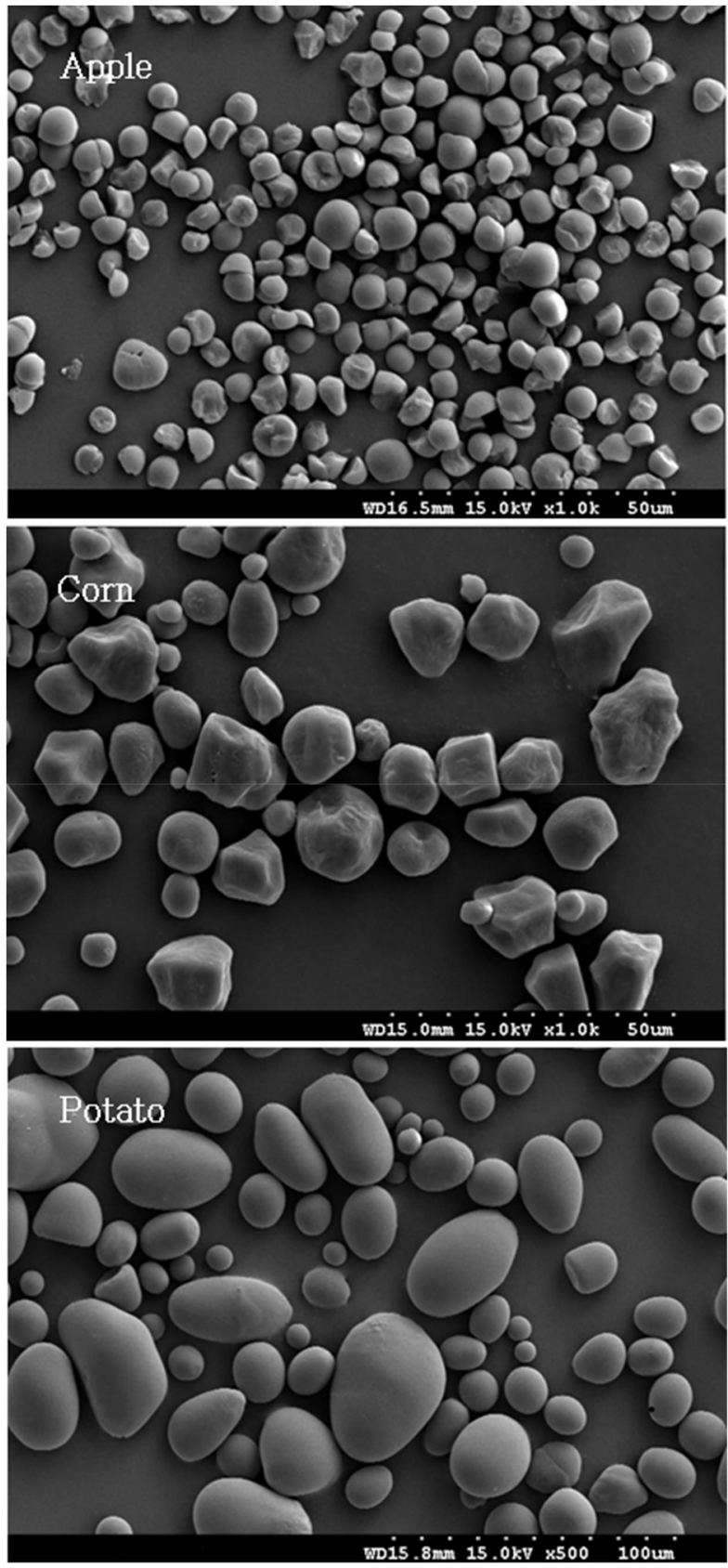

Fig. 1. Scanning electron micrographs of starch granules isolated from 'Fuji'‘' apple, corn, and potato.

shape as they were degraded during maturity and increased storage periods (Kovacs and Eads, 1999).

Similar to the chemical components, the starch granule size influences its functional properties (Singh et al., 2003). The granule size of the apple, corn, and potato starches are listed in Table 1. The mean starch granule size was the smallest for the 'Fuji' apple starch $(7.5 \mu \mathrm{m})$ and the largest for the potato starch $(35.2 \mu \mathrm{m})$. The mean granule size of 'Fuji' apple starch was approximately midway between those of 'Gala', 'Golden Delicious', 'Granny Smith', 'Jersey Mac', 'Jonagold', and 'Royal Gala' apple starches ( $2 \mu \mathrm{m}$ to $12 \mu \mathrm{m}$ ) (Stevenson et al., 2006). The granule size of unripe and ripe 'Mutsu' apple starches was reported to be 15-40 $\mu \mathrm{m}$, indicating that the area and perimeter of the apple starch granules decreases with an increasing storage period or maturity (Kovacs and Eads, 1999). In addition to apple variety, maturity, and storage period, differences in granule size may be observed due to the use of different methods for measuring the size of the particles, which include laser diffraction particle size analysis, SEM (Stevenson et al., 2006), and image analyses (Kovacs and Eads, 1999).

\section{Comparison of $\mathrm{X}$-ray diffraction patterns}

$\mathrm{X}$-ray diffractometry was used to investigate the presence and characteristics of the crystalline structure of the starch granules (Singh et al., 2003). The X-ray diffraction pattern of 'Fuji' apple starch shows characteristic peaks of both A-type $\left(2 \theta=15.36^{\circ}\right.$ and $\left.23.11^{\circ}\right)$ and B-type $\left(2 \theta=5^{\circ}\right.$ and $17.28^{\circ}$ ) starch. This A/B-type mixture, a C-type X-ray diffraction pattern, observed for 'Fuji' apple starch has also been observed for starch obtained from 'Gala', 'Golden Delicious', 'Granny Smith', 'Jersey Mac', 'Jonagold', and 'Royal Gala' apples (Stevenson et al., 2006). Corn starch showed a typical A-type X-ray diffraction pattern, with strong peaks at 15.37 and $23.09^{\circ}$, while potato starch showed a typical B-type X-ray diffraction pattern, with weak peaks at 5.6 and $22-23^{\circ}$, and a strong peak at $17^{\circ}$ (Fig. 2). It is well known that cereal starches show a typical A-type $\mathrm{X}$-ray diffraction pattern, whereas tuber starches show a B-type X-ray pattern (Singh et al., 2003).

\section{Comparison of swelling power and solubility}

The swelling power and solubility of starch are temperaturedependent properties that increase with an increasing temperature because of the weakening of the internal associative forces maintaining its granular structure (Kong et al., 2015). The swelling powers of potato, apple, and corn starches were relatively steady between $40^{\circ} \mathrm{C}$ and $50^{\circ} \mathrm{C}$ but were increased at $60^{\circ} \mathrm{C}$. The swelling powers increased in the order of potato $>$ apple $>$ corn starch (Fig. 3). This increase in swelling power results from the decrystallization of the 


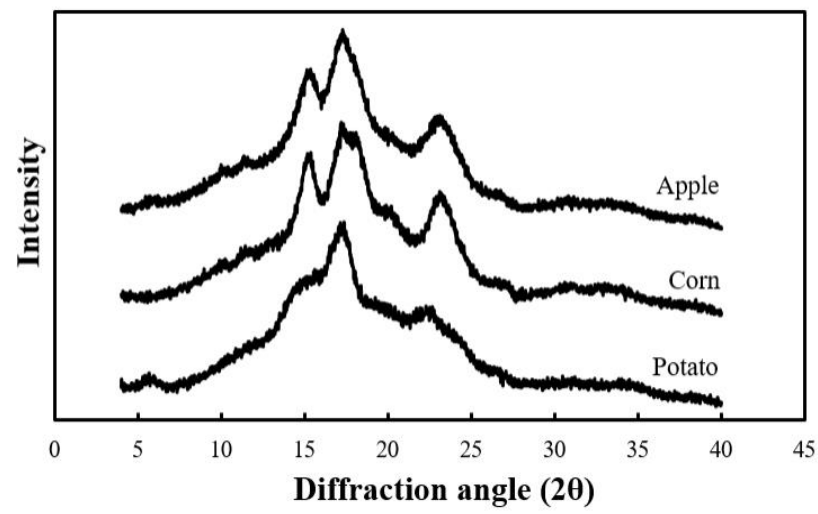

Fig. 2. X-ray diffraction patterns of 'Fuji' apple, com, and potato starches.
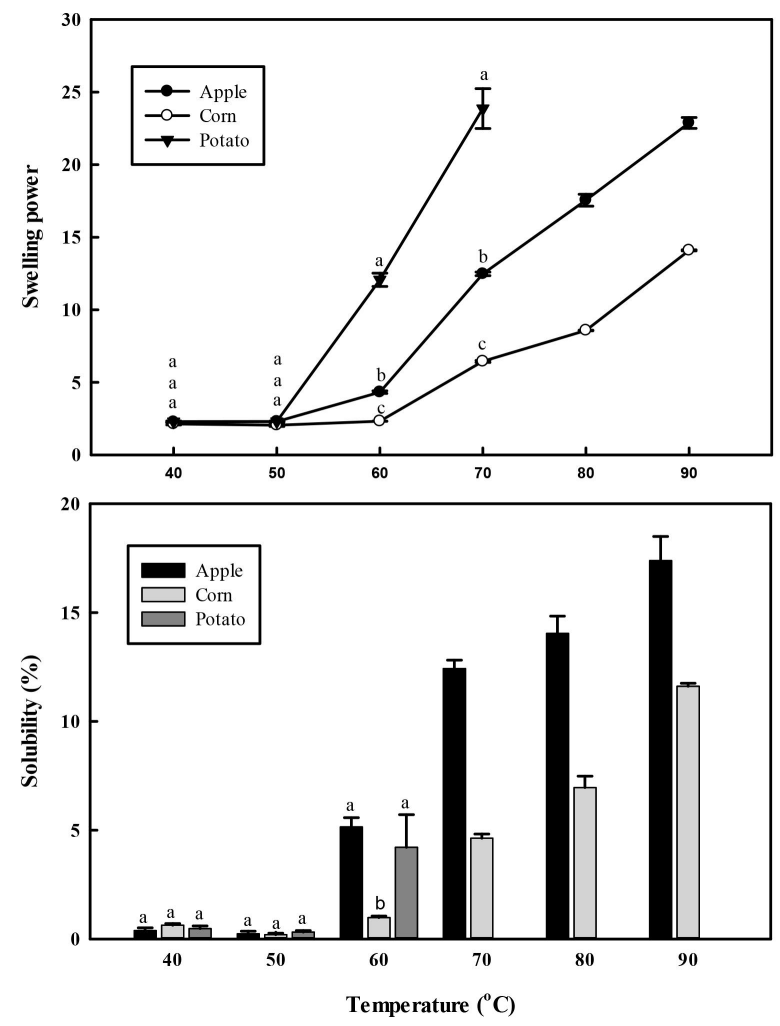

Fig. 3. Swelling power and solubility of 'Fuji' apple, corn, and potato starches.

Mean \pm SD ( $n=3$ ) with a different letter above the bar indicating significant difference as determined by Duncan's multiple range test $(\mathrm{p}<0.05)$.

starch granule crystalline region and is closely linked to the gelatinization temperature. As the temperature increases, the binding forces decrease, enhancing the mobility of starch granules (Jyothi et al., 2010; Leach et al., 1959). Tester and
Morrison (1990) reported that the starch swelling powers increase with increasing amylopectin content and the size of the amorphous region of starch. Potato starch is reported to have high swelling power, which is likely associated with the high content of phosphate groups on its amylopectin (Singh et al., 2003). The results of this experiment were similar to the phosphorus content results (Table 1). The observed increase in swelling power resulted from the decrystallization of the starch granule crystalline structures, which led to an increased mobility of the starch granules due to the reduced binding forces associated with the rising temperatures, which was related to their gelatinization temperatures (Jyothi et al., 2010; Leach et al., 1959).

The solubilities of the apple, corn, and potato starches are presented in Fig. 3. Potato starch solubility was unstable at $60^{\circ} \mathrm{C}$ and could not be measured at more than $70^{\circ} \mathrm{C}$ because the sediment and supernatant were not separated for measurement. The starch solubility remained constant until $50^{\circ} \mathrm{C}$ but increased at $60^{\circ} \mathrm{C}$, similar to the result obtained for the swelling power (Fig. 3). Increases in solubility with increasing temperature were observed to be faster in apple starch than in corn starch. This may be due to differences in the amylose content of these starches (Table 1). Higher amylose content in starch granules has been reported to increase the solubilization capacity in an aqueous solution due to its leaching at high temperatures (de Barros Mesquita et al., 2016).

\section{Comparison of pasting properties}

The pasting properties of starch play an essential role in selecting a starch source for industrial use. These were investigated and are listed in Table 2 . The peak viscosity and breakdown of the 'Fuji' apple starch were 450.5 RVU and 133.8 RVU, respectively which was higher than those of corn starch (255.1 RVU and 90.1 RVU) and lower than those of potato starch (815.8 RVU and 735.2 RVU). This high level of peak viscosity and breakdown in potato starch is consistent with the findings previously reported by Noda et al. (2004). The difference in peak viscosity and breakdown of apple starch and corn starch might be due to the differences in the phosphorus content (Table 1). Among the three starch types, apple starch had the highest hold and final viscosity values. Additionally, the apple starch was similar to corn starch in terms of breakdown viscosity and 
Table 2. Pasting properties of 'Fuji' apple, com, and potato starches

\begin{tabular}{cccc}
\hline Properties $^{1)}$ & Apple starch & Corn starch & Potato starch \\
\hline Peak viscosity (RVU) & $450.47 \pm 21.74^{\mathrm{b} 2}$ & $255.06 \pm 20.27^{\mathrm{c}}$ & $815.78 \pm 35.37^{\mathrm{a}}$ \\
Hold viscosity (RVU) & $316.64 \pm 7.02^{\mathrm{a}}$ & $165.09 \pm 2.53^{\mathrm{b}}$ & $80.58 \pm 4.25^{\mathrm{c}}$ \\
Breakdown (RVU) & $138.83 \pm 14.72^{\mathrm{b}}$ & $89.97 \pm 17.74^{\mathrm{b}}$ & $735.20 \pm 31.12^{\mathrm{a}}$ \\
Final viscosity (RVU) & $430.83 \pm 7.33^{\mathrm{a}}$ & $263.36 \pm 17.55^{\mathrm{b}}$ & $285.25 \pm 24.35^{\mathrm{b}}$ \\
Setback (RVU) & $114.19 \pm 0.31^{\mathrm{b}}$ & $98.27 \pm 15.02^{\mathrm{b}}$ & $204.67 \pm 20.10^{\mathrm{a}}$ \\
Peak time (min) & $4.73 \pm 0.07^{\mathrm{b}}$ & $5.09 \pm 0.10^{\mathrm{a}}$ & $3.16 \pm 0.10^{\mathrm{c}}$ \\
Pasting temperature $\left({ }^{\circ} \mathrm{C}\right)$ & $70.17 \pm 1.03^{\mathrm{b}}$ & $77.08 \pm 0.65^{\mathrm{a}}$ & $65.82 \pm 0.10^{\mathrm{c}}$ \\
\hline
\end{tabular}

${ }^{1)}$ Breakdown, peak viscosity-hold viscosity; Setback, final viscosity-hold viscosity; RVU, rapid visco-analyzer units.

${ }^{2}$ Means \pm SD $(n=3)$ in a row followed by the same letter are not significantly different by Duncan's multiple range test ( $p<0.05$ ).

setback. Because the setback of apple starch was lower than that of potato starch, the retrogradation of apple starch was expected to be slower than that of potato starch. The peak time was the shortest in potato starch, the longest in corn starch. The pasting temperature of apple starch was $70.2^{\circ} \mathrm{C}$, which was lower than that of corn starch $\left(77.1^{\circ} \mathrm{C}\right)$, but higher than that of potato starch $\left(65.8^{\circ} \mathrm{C}\right)$. The reported pasting temperatures of 'Gala' and five other apple cultivar starches ranged from 69.9 to $71.3^{\circ} \mathrm{C}$ (Stevenson et al., 2006). The above results suggest that the high viscosity of potato starch pastes was maintained for a sort period and that of the apple starch pastes was maintained for extended period. This property is available for the utilization of apple starches. Apart from the pasting temperature, further comparisons between the pasting properties of 'Fuji' apple starch and other apple varieties (Stevenson et al., 2006) could not be performed because of the notable differences in the experimental conditions used of these studies.

\section{Comparison of In vitro digestibility}

The In vitro digestibilities of the apple, corn, and potato starches are listed in Table 3. Apple starch had the highest In vitro digestibility among the three starches at $180 \mathrm{~min}$. The RDS content of apple starch was $34.3 \%$, which was significantly higher than those of corn $(26.2 \%)$ or potato $(13.4 \%)$ starch $(\mathrm{p}<0.05)$. Comparatively, the SDS content of apple starch was the highest among the three samples, resulting in the lowest RS content. The In vitro digestibility of starch derived from other apple varieties has not yet been reported. In general, starch digestibility decreases with an increasing amylose content (Singh et al., 2010). However, the particle size of starch exerts a greater digestibility effect than the amylose content, with smaller particles resulting in increased digestibility. This is likely due to the enhanced binding of the enzyme to smaller particles with an increased surface area (Langworthy and Deuel, 1922; Tester et al., 2006). Therefore, the high digestibility of 'Fuji' apple starch may be explained by its small particle size (Table 1). This characteristic can be applied to fields that require a rapid digestion.

\section{Comparison of syneresis}

The syneresis of the starch gels after freeze-thaw treatment is presented in Fig. 4. The syneresis of all three starches increased with an increasing number of freeze-thaw cycles. The syneresis curves showed a gradual increase as the freeze-thaw cycles were repeated, probably because the starch syneresis was close to its maximum or entered a stage of stagnation due to repeated freezing and thawing (Baker and Rayas-Duarte, 1998). The syneresis of apple starch was the lowest, indicating the highest freeze-thaw stability (Wang et al., 2013). Physical changes due to freeze-thawing of the starch gel are related to moisture retention and retrogradation of starch (Majzoobi et al., 2016). Therefore, it is presumed that retrogradation of apple starch with the lowest syneresis is slow. This result is consistent with the prediction that the apple retrogradation of apple starch is slower than that of potato starch because the setback of apple starch was lower than that of potato starch (Table 2).

In conclusion, the chemical, morphological, pasting, 
Table 3. In vitro digestibility of 'Fuji' apple, corn, and potato starches

\begin{tabular}{|c|c|c|c|c|}
\hline \multicolumn{2}{|c|}{ Properties } & \multirow{2}{*}{$\begin{array}{c}\text { Apple starch } \\
0.00\end{array}$} & \multirow{2}{*}{$\begin{array}{c}\text { Corn starch } \\
0.00\end{array}$} & \multirow{2}{*}{$\begin{array}{c}\text { Potato starch } \\
0.00\end{array}$} \\
\hline & $0 \min$ & & & \\
\hline & $20 \mathrm{~min}$ & $34.26 \pm 1.62^{\mathrm{al})}$ & $26.22 \pm 0.63^{b}$ & $13.43 \pm 0.91^{\mathrm{c}}$ \\
\hline \multirow[t]{3}{*}{ Digestibility (\%) } & $60 \mathrm{~min}$ & $54.57 \pm 0.93^{\mathrm{a}}$ & $40.71 \pm 1.54^{\mathrm{b}}$ & $18.52 \pm 0.77^{\mathrm{c}}$ \\
\hline & $120 \mathrm{~min}$ & $63.02 \pm 1.80^{\mathrm{a}}$ & $47.63 \pm 0.95^{\mathrm{b}}$ & $22.01 \pm 0.94^{\mathrm{c}}$ \\
\hline & $180 \mathrm{~min}$ & $65.90 \pm 0.26^{\mathrm{a}}$ & $49.79 \pm 2.31^{\mathrm{b}}$ & $22.51 \pm 1.43^{\mathrm{c}}$ \\
\hline \multicolumn{2}{|c|}{ Rapidly digestible starch (RDS, \%) } & $34.26 \pm 1.62^{\mathrm{a}}$ & $26.22 \pm 0.63^{b}$ & $13.43 \pm 0.91^{\mathrm{c}}$ \\
\hline \multicolumn{2}{|c|}{ Slowly digestible starch (SDS, \%) } & $28.76 \pm 2.22^{\mathrm{a}}$ & $21.41 \pm 1.54^{b}$ & $8.58 \pm 0.92^{\mathrm{c}}$ \\
\hline \multicolumn{2}{|c|}{ Resistant starch (RS, \%) } & $36.98 \pm 1.80^{\mathrm{c}}$ & $52.37 \pm 0.95^{\mathrm{b}}$ & $77.99 \pm 0.94^{\mathrm{a}}$ \\
\hline
\end{tabular}

${ }^{1)}$ Means \pm SD $(n=3)$ in a row followed by the same letter are not significantly different by Duncan's multiple range test $(\mathrm{p}<0.05)$.

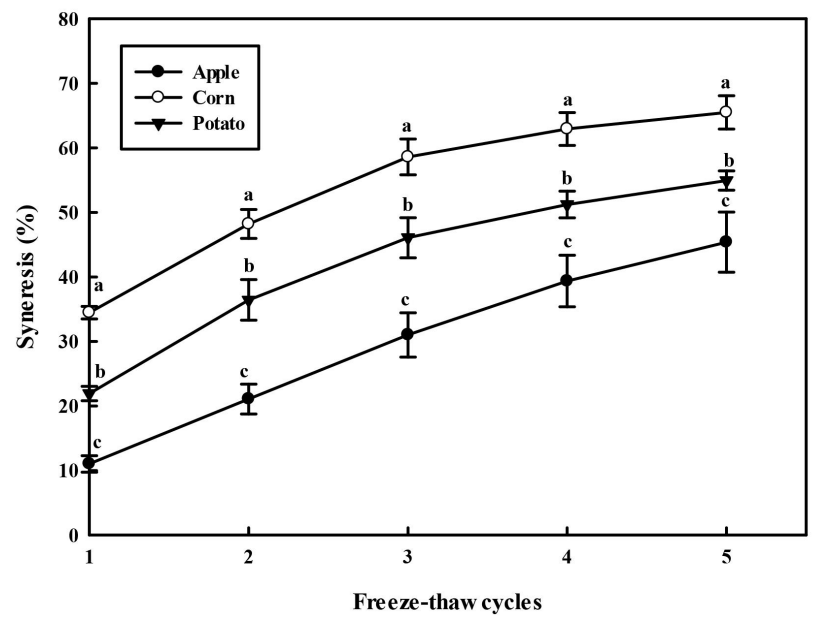

Fig. 4. Syneresis of 'Fuji' apple, corn, and potato starches.

Mean \pm SD ( $n=3$ ) with a different letter above the bar indicating significant difference as determined by Duncan's multiple range test $(p<0.05)$.

digestive, and syneresis properties of the starches isolated from thinned young 'Fuji' apples, corn, and potatoes were analyzed and compared. The granules of apple starch were spherical, hemispherical, and broken spherical and revealed C-type X-ray diffraction patterns, unlike those of corn (A-type) and potato (B-type) starches. The mean particle size of the apple starch granules was the smallest among all the starches studied. Apple starch had higher hold and final viscosities, a lower syneresis, and a higher In vitro digestibility, than the other two starches. The phosphorus content, swelling power, and pasting temperature values of the apple starch were between those of the potato and corn starches. These results indicate that apple starch forms a paste or gel with long-term high viscosity and digestibility, which leads to a retrogradation delay. These unique properties of young 'Fuji' apple starch could support a wide range of uses, although further research is required before its industrial application.

\section{Conflict of interests}

The authors declare no potential conflict of interest.

\section{ORCID}

Hun-Sik Chung https://orcid.org/0000-0003-1990-9575

\section{References}

Alcazar-Alay SC, Meireles MAA. Physicochemical properties, modifications and applications of starches from different botanical sources. Food Sci Technol, 35, 215-236 (2015)

Baker LA, Rayas-Duarte P. Freeze-thaw stability of amaranth starch and the effects of salt and sugars. Cereal Chem, 75, 301-307 (1998)

Chun IJ, Zheng WW, Choi C, Song YY, Kwang IK, Hirst P. Multiple applications of lime sulfur for fruit thinning of 'Fuji' and 'Hongro' apple trees. J Bio-Env Con, 21, 445-451 (2012)

de Barros Mesquita C, Leonel M, Franco CM, Leonel S, Garcia EL, Dos Santos TP. Characterization of banana starches obtained from cultivars grown in Brazil. Int $\mathrm{J}$ Biol Macromol, 89, 632-639 (2016) 
Duan DX, Donner E, Liu Q, Smith DC, Ravenelle F. Potentiometric titration for determination of amylose content of starch - A comparison with colorimetric method. Food Chem, 130, 1142-1145 (2012)

Englyst HN, Kingman SM, Cummings JH. Classification and measurement of nutritionally important starch fractions. Eur J Clin Nutr, 46, S33-50 (1992)

Fan X, Mattheis JP, Patterson ME, Fellman JK. Changes in amylose and total starch content in 'Fuji' apples during maturation. HortScience, 30, 104-105 (1995)

Gorin N, Bonisolli F, Heidema FT, Klop W, Williams AA. Changes in starch content and amylase zymograms during storage of golden delicious and Cox's orange pippin apples. Eur Food Res Technol, 166, 157-161 (1978)

Jyothi AN, Sajeev MS, Sreekumar JN. Hydrothermal modifications of tropical tuber starches. 1. Effect of heatmoisture treatment on the physicochemical, rheological and gelatinization characteristics. Starch, 62, 28-40 (2010)

Kong X, Zhu P, Sui Z, Bao J. Physicochemical properties of starches from diverse rice cultivars varying in apparent amylose content and gelatinisation temperature combinations. Food Chem, 172, 433-440 (2015)

Kovacs E, Eads TM. Morphologic changes of starch granules in the apple cv. Mutsu during ripening and storage. Scanning, 21, 326-333 (1999)

Langworthy CF, Deuel HJ. Digestibility of raw rice, arrowroot, canna, cassava, taro, tree-fern, and potato starches. J Biol Chem, 52, 251-261 (1922)

Leach H, McCowen D, Schoch T. Swelling and solubility patterns of various starches, structure of starch granules. Cereal Chem, 36, 534-544 (1959)

Majzoobi M, Kaveh Z, Farahnaky A. Effect of acetic acid on physical properties of pregelatinized wheat and corn starch gels. Food Chem, 196, 720-725 (2016)

Mannucci A, Serra A, Remorini D, Castagna A, Mele M, Scartazza A, Ranieri A. Aroma profile of Fuji apples treated with gelatin edible coating during their storage. LWT-Food Sci Technol, 85, 28-36 (2017)

Noda T, Tsuda S, Mori M, Takigawa S, Matsuura-Endo C, Saito K, Hetti W, Mangalika A, Hanaoka A, Suzuki Y, Yamauchi $H$. The effect of harvest dates on the starch properties of various potato cultivars. Food Chem, 86, 119-125 (2004)

Ohmiya A, Kakiuchi N. Quantitative and morphological studies on starch of apple fruit during development. J Japan Soc Hort Sci, 59, 417-423 (1990)

Sarka E, Dvoracek V. New processing and applications of waxy starch (a review). J Food Eng, 206, $77-87$ (2017)

Schoch TJ. Swelling power and solubility of granular starches. In: Methods in Carbohydrate Chemistry, IV: Starch. Whistler RL (Editor), Academic Press, New York, USA, p 106-108 (1964)

Singh J, Dartois A, Kaur L. Starch digestibility in food matrix: A review. Trends Food Sci Technol, 21, 168-180 (2010)

Singh N, Singh J, Kaur L, Sodhi NS, Gill BS. Morphological, thermal and rheological properties of starches from different botanical sources. Food Chem, 81, 219-231 (2003)

Song KJ, Hwang JH, Yun HK. Changes of soluble sugar and starch concentrations in fruits of apple cultivars differing in maturity. Hortic Environ Biotechnol, 44, 207-210 (2003)

Stevenson D, Domoto P, Jane J. Structures and functional properties of apple (Malus domestica Borkh) fruit starch. Carbohydr Polym, 63, 432-441 (2006)

Tester RF, Morrison WR. Swelling and gelatinization of cereal starches. 1. Effects of amylopectin, amylose, and lipids. Cereal Chem, 67, 551-557 (1990)

Tester RF, Qi X, Karkalas J. Hydrolysis of native starches with amylases. Anim Feed Sci Technol, 130, 39-54 (2006)

Wang L, Xie B, Xiong G, Wu W, Wang J, Qiao Y, Liao L. The effect of freeze-thaw cycles on microstructure and physicochemical properties of four starch gels. Food Hydrocoll, 31, 61-67 (2013)

Williams PC, Kuzina FD, Hlynka I. A rapid colorimetric procedure for estimating the amylose content of starches and flours. Cereal Chem, 47, 411-420 (1970)

Zheng HZ, Kim YI, Chung SK. A profile of physicochemical and antioxidant changes during fruit growth for the utilisation of unripe apples. Food Chem, 131, 106-110 (2012) 